\title{
Spaces of encounter
}

\section{Digital autonomy and social fragmentation}

\section{Space of encounter}

Hugh Campbell's article on Hans Scharoun's Philharmonie (arq 11/2, pp. 159-166) elegantly locates the building in the political and sociological contexts of post-war Germany. It also draws attention to the influence on Scharoun's unique conceptions of architectural space of the German art historical tradition of Wölfflin, Lipps, Worringer and Arnheim and the socio-philosophical ideas of Martin Buber, whose term 'space of encounter' beautifully captures the essence of Scharoun's 'flowing, aperspectival spaces'. I have visited the Philharmonie a number of times and my direct experience of the building - as one arrives before a concert, moves to the auditorium, returns to the foyers at the interval and, finally, returns to the city perhaps offers some empirical corroboration of Dr. Campbell's theoretical analysis.

Upon arrival in the wide draught lobby you glimpse the

'aperspectival' foyers beyond. First, however, you are invited, maybe instructed is a better term, to deposit your coat at the extensive and unavoidable cloakrooms. But the efficiency of the cloaks service barely detracts from your growing anticipation as you look ahead. The reality of the foyer amply fulfils the characterisation of Dr. Campbell's account. The process by which the growing company gathers in large and small groups, takes refreshment, exchanges greetings is wondrously informed by the topography of the space. Then, the procession to the auditorium is easy and fluid as the disposition of the staircases reveals a subtle and legible logic that reaches fulfilment at the point where you first enter the splendour of the auditorium. The foyers are, as would be expected, equally effective during interval breaks. Then, if this is not too fanciful, I have detected an even greater sense of

'encounter'. What has struck me most is the capacity of the space to contain hugely diverse social relationships. Large groups, perhaps corporate parties, find appropriate places for pressing flesh, or whatever it is that they do. Young and old seem equally comfortable and it seems that more intimate liaisons might be discreetly enjoyed in the more peripheral territories. At the end of the evening the return to the everyday condition of the city is nicely contrived, not too quickly, with time and space for goodbyes and your coat is easily retrieved. The fine images accompanying Dr. Campbell's essay hint at something of this, but the complex experience of such spaces demands a different descriptive narrative and, ideally, first-hand experience.

These observations are, of course, 'unscientific' and rely on recall of occasions over a number of years, when the focus has been on the anticipation and then the experience of music making (sadly, in my case, without the promise of an intimate liaison at the interval). But that, perhaps, is sufficient validation and the apparatus of an organised research study, with questionnaires, time-lapse photography and other such paraphernalia might not take us to the heart of the matter.

On some further matters, I am intrigued by Dr. Campbell's interest in Herbert von Karajan's relation to the building and look forward to reading the outcome of this in due course. The coincidence of

Karajan's 22 years with the Berlin Philharmonic Orchestra and the

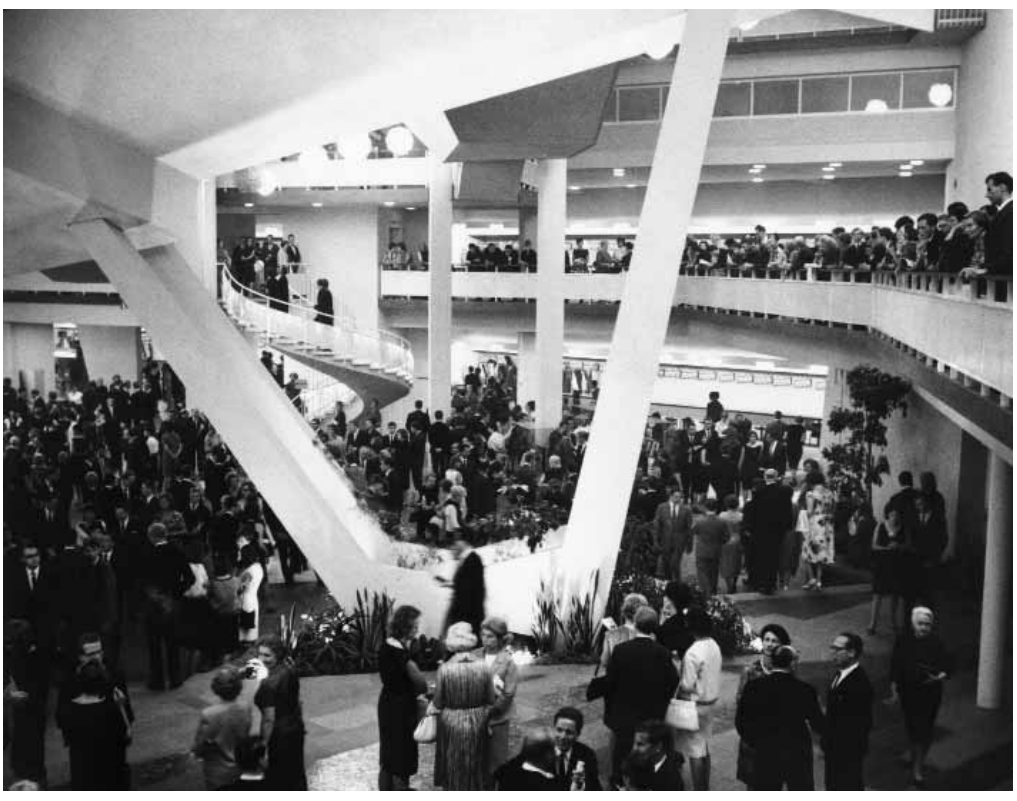

Lobby of Hans Scharoun's Berlin Philharmonie (Bildarchiv Preussicher Kulturbesitz, photograph by Liselotte and Armin Orgel-Köhne, Berlin, 1964) 
conception of the building offers the prospect of insights into both the architecture and the evolution of German musical culture in the twentieth century. For what it's worth, I have long been struck by the coincidence of the almost central location of the conductor's podium in the hall and Karajan's image as the most narcissistic of all modern maestri! I have no objective data to offer on the question of the acoustics of the Philharmonie, and here this is a prerequisite of proper comment, but I can report that I have found the sound to be magical. It seems to hover before you rather than enter your ears directly, precisely the impression of the "immersive acoustic' that Dr. Campbell describes. The physical propagation of direct and reflected sound is seemingly transformed by Scharoun's and Lothar Cremer's design and is less apparent than in more conventional halls, wonderful though these can be.

I have recently had the pleasure of reviewing the restoration of the Royal Festival Hall in London (Architectural Review, November 2007). Designed by Leslie Martin, Peter Moro and colleagues at the London County Council Architect's Department, it opened in $1951 \mathrm{a}$ mere 12 years before the Philharmonie. I have a longer and deeper familiarity with the London building and am convinced of its considerable, if different virtues, both before and after the recent works. In its conception RFH is symmetrical, formal, and explicitly objective in its rationality. Unlike the Philharmonie, which is normally only open before concerts, the foyers are open to all comers from morning to night, quite independently from the concert programme, and in this, they continue after over half a century successfully to reflect the socio-political aspirations of the post-war Labour government and its allies at the London County Council. The relation of social encounter and architectural topography in the two buildings is quite different and, perhaps, a comparative study of the two buildings might draw out yet more insights into the nature of this endlessly fascinating building type. Maybe this might happen?

DEAN HAWKES Cambridge

Dean Hawkes is Emeritus Professor at the Welsh School of Architecture, Cardiff University and Emeritus Fellow of Darwin College, Cambridge.

\section{Relative sustainability}

In response to Jess Hrivnak's paper 'Is relative sustainability relevant?' (arq 11/2, pp. 167-176); yes, relative sustainability is relevant. However, it is an obligation and responsibility of the architect to push for sustainable best practice.

First, the definition of sustainability, although currently subjective and notoriously difficult to quantify, does require a moment's thought. It is perhaps the definition of sustainability that lies at the heart of the question 'Is relative sustainability relevant?' and it is ' $a$ ' definition that will provide a relative position from which this response is generated. It is also arguable that the unclear 'woolly term' is the underlying reason why the paper is posed as a question. The relativity of the 'application' of sustainability is reliant upon the shared understanding of the term, from the design team to the wider arena of the 'general public'.

From a 'purist's' perspective sustainability is simply that which can be sustained entirely from within the building's associated plot. An example would be a building where energy requirements are reduced by efficient design (day-lit, naturally ventilated, highly insulated, airtight); that generates the requisite renewable-energy for occupancy demands, incorporating ease of use and responsiveness for the operator; that has reduced 'embodied energy' impact through the use of renewable, locally sourced materials; that reduces operating resource waste through specification of 'best practice' efficient strategies; that responds to 'human environmental' needs through the inclusion of hygroscopic materials and naturally breathing walls; that has no, or positive, impact on local ecosystems, flora and fauna; that educates through application of 'best practice' sustainable strategies; and that 'delights' and invites use, empowering a sense of local social energy.

Architectural sustainable design requires a 'holistic' approach that underpins and informs all aspects of the design, construction and occupancy of a building. It is this holistic approach, requiring a thorough examination of all interconnected parts of the design, construction and occupancy and their individual impact upon each other while incorporating a measure of commitment and conviction to that unifying vision throughout, that enables realisation of sustainable architecture.

As sustainable design moves into the mainstream there remains an obligation toward aesthetic merit, currently derived from historic (and decadent - some would say) modernist paradigms of 'machine made', steel, glass and 'white' clean lines of rigorous order and geometry. However, aesthetic considerations should not, and do not have to be to the detriment of sustainable strategies. Sustainable design brings its own palette of languages to the mix; it is the architect's challenge to blend these languages to suit the required aesthetic.

The decision of the architect of 'Inn the Park' to prioritise aesthetics above 'any' environmental consideration demonstrates a lack of holistic design, conviction and commitment to a fully sustainable remit. Could it be that Hopkins have compromised a lot because they do not have a strong enough ecological agenda to which they are committed? Even with a deficit of

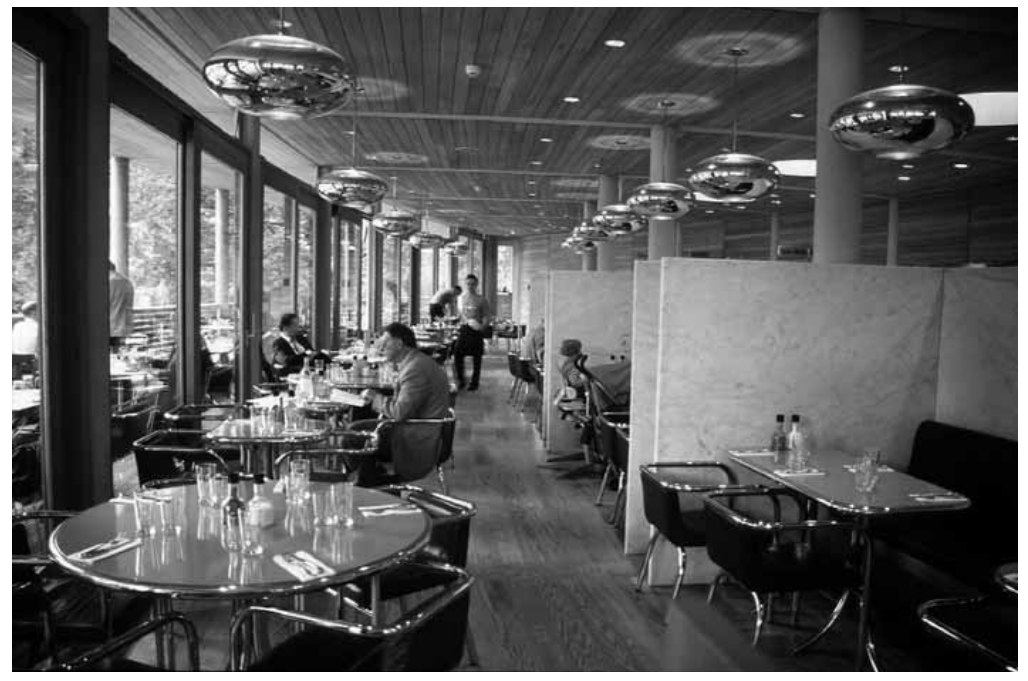

Hopkins Architects, 'Inn the Park’, St. James’s Park, London 
sustainable design, however, the building manages to communicate ecological intentions. The danger of compromising the sustainable agenda here is that a reasonably high profile building transmits a powerful message that complacent sustainable design is acceptable. Is it acceptable?

It is not always within the architect's remit to evaluate postoccupancy user performance of the buildings they design, or to socially engineer responses to

unsustainable practices (restaurants, supermarkets etc.) within the building. However, with sustainable thinking at the heart of the design process, many strategies and potential implications can be aired through the consultative process of holistic design and considered for possible action. The architect has a duty to inform the client and users of best practice throughout all aspects of the design process, resulting in a wellinformed user group who in turn can better contribute to the design process and educate others in addition to eventually getting the most from their building.

The new Architype West office building (winner of the RIBA Sustainability Award 2007), a converted barn and cowshed, is a good example of sustainable architecture in practice. All materials are sourced locally and erected by local builders. The heating (space and water) is provided by a wood-chip boiler and water efficient appliances are installed. The building is superinsulated with enough thermalmass to moderate temperature fluctuation efficiently. A natural ventilation strategy is employed and daylighting and solar gains maximised during the colder months. All materials and finishes are natural; the architecture delights and inspires through a simple modern contemporary aesthetic derived from the language of sustainability, site, brief and tectonic.

Further to this and perhaps as important is the mind-set of the users who seek to advance the building's remit into their own lives. Many cycle to work, grow vegetables in the newly created vegetable patch, source food locally, and recycle everything (including food scraps on the compost heap).

The building is also an educational 'open house' for groups of students and professionals alike, as well as casual visitors, clients and other consultants. The merits of sustainable design and contemporary design aesthetic are successfully transmitted through the building alone.

As has already been argued, 'pure' sustainable architecture is unlikely to be realised in the commercial arena, particularly if it is to be used as a restaurant or supermarket, however there are minimum acceptable standards of sustainability that are currently achievable with sufficient conviction and commitment.

How relevant is relative?

Nowhere near relevant enough given our current climate; a vision for humane, ecological, environmentally and socially responsive, energy-efficient architecture will naturally generate new architectural languages and educate by default; I believe this is the truly relevant relative.

As sustainable architecture becomes increasingly important in our battle against climate change it is vital that we seek to raise the standards of sustainable practice and not let ourselves succumb to the veneer of 'bolt-on-eco'. The blithe use of sustainable architectural language merely serves to lessen the relevance of relative sustainability and weaken the efforts of the industry as a whole.

ADRIAN SCHOLEFIELD Great Malvern

Adrian Scholefield writes on behalf of Architype Ltd., where he works as Architectural Assistant.

\section{Architectural guidebooks: a Cheshire cat}

Reading Alan Day and Vaughan Hart's paper addressing the future of architectural guidebooks (arq 11/2, pp. 151-8), I was curious to find that its preoccupations seemed to typify late modernity: namely with history, autonomy and technology. I'll return to these, but my first concern is to respond to notions of the nature and purpose of architectural guidebooks that the authors touched on, and the nature and purpose of their exhibition, which I think as a representation of the city is something else besides.

The authors' article then is not so much about architectural guidebooks per se as it is about their proposal for an exhibition about Palladio's guides to Rome, in their view the first guides of the modern era and model for those subsequently that organised ' [...] the material into logical routes which the tourist could follow'.
The description of their provocative proposal is sandwiched between two interesting sections; an introductory one giving a fascinating description of Palladio's guidebooks themselves, and the second a speculation about what guidebooks might consist of in the digital future. Nevertheless this description seems independent of both sections in that the centrepiece of their proposed exhibition, a digital model of Rome in around $155^{\circ}$, is an attempt at a comprehensive representation of the city at this time derived from many contemporaneous sources rather than simply allowing "the visitor to appreciate the city's monuments through his [Palladio's] words alone'.

One of these other sources, key to the city's visualisation in the model is Pirro Ligorio's map of Rome of 1552, like it an ambitious exercise in putting together a comprehensive view, yet unlike it not aiming at the same icing-sugar homogeneity of representation or dimensional consistency (I do appreciate that the rendering of the model is not yet complete).

An interesting thing about Ligorio's map is its very inconsistency as a drawing. Compositionally it is laid out as a topographical site plan of the whole city; however each of the key monuments and buildings is lovingly rendered as a mnemonic image in perspectivised elevation a mixture of at least two projective techniques, neither of which is rigorously applied. Consequently it is far more fascinating to look at and inhabit imaginatively than any systematically measured map, although strictly not as useful.

On the other hand it is precisely these disjunctions of dimension, scale and point of view generated by the way in which it is drawn that open the gaps where we can 'read between the lines' and inhabit Rome with our own resonances and associations.

Looking again at the computer model of Rome, I wonder if the 'richer environment' the authors hope for can in fact be provided by such a homogeneous representational tool

Surely its virtues of consistency, its ability to show us a reconstruction of the city at a moment in its history (c.1550) both from the air and at ground level, as a whole and as a successive sequence of vistas, is a triumph of a sort,

'[...] thus illustrating again for the first time how the ancient remains located alongside the churches on 
each route [Palladio's] could have been appreciated by the sixteenthcentury visitor.'

But it tells us much more about how we see and understand cities now than how they were seen and understood then (for which I would go straight to Ligorio and be guided by him).

Is a model of Rome in 1550 that you can apparently 'fly through' appropriate as an attempt to evoke historical reality? I suspect Ligorio was more interested in how Rome might look to his God, simultaneous in both its entirety and in its minutiae, than in how accurately man's general overview of the city from particular co-ordinates in the air could be depicted - what could possibly be the point of that! I believe it is a mistake to call Ligorio's 'an aerial view'.

The decision has been made for the virtual model to be presented as a non-interactive four-minute animation. One can see practically why this must be so, but doing this denies the viewer's imaginative participation even more so than an actual static drawing or model would, it puts it beyond reach. It is as though the model's creators are unwilling to let it out of their possession, controlling absolutely the viewer's experience of sixteenth-century Rome and contrary to the stated vision the authors have for digital technology:

'New kinds of city guides can be invented based on the visitor's

freedom of choice and desire to roam.' There is an important political point here: whereas the traditional guidebook encourages exploration, the exhibition, being for presentation to a crowd rather than to its separate individuals, requires of them passivity; it seems that spaces of the actual city may be used differently by different people, even contested, while the space of exhibition cannot entertain the awkwardness of conflicting interests or even discussion.

Perhaps there is nothing at all wrong in this but the model in itself therefore is not a guidebook nor the equivalent or enhancement of one, although it may well be among the data that the visitor could reference while roaming in situ one day in the digital future.

\section{Why is this?}

Guidebooks surely, as the authors say "[...] still present a view of the city which is that of a single individual'. Moreover, as the term 'guide' implies, for there to be a guide there must be one who is guided too. This is a human relationship, even if a

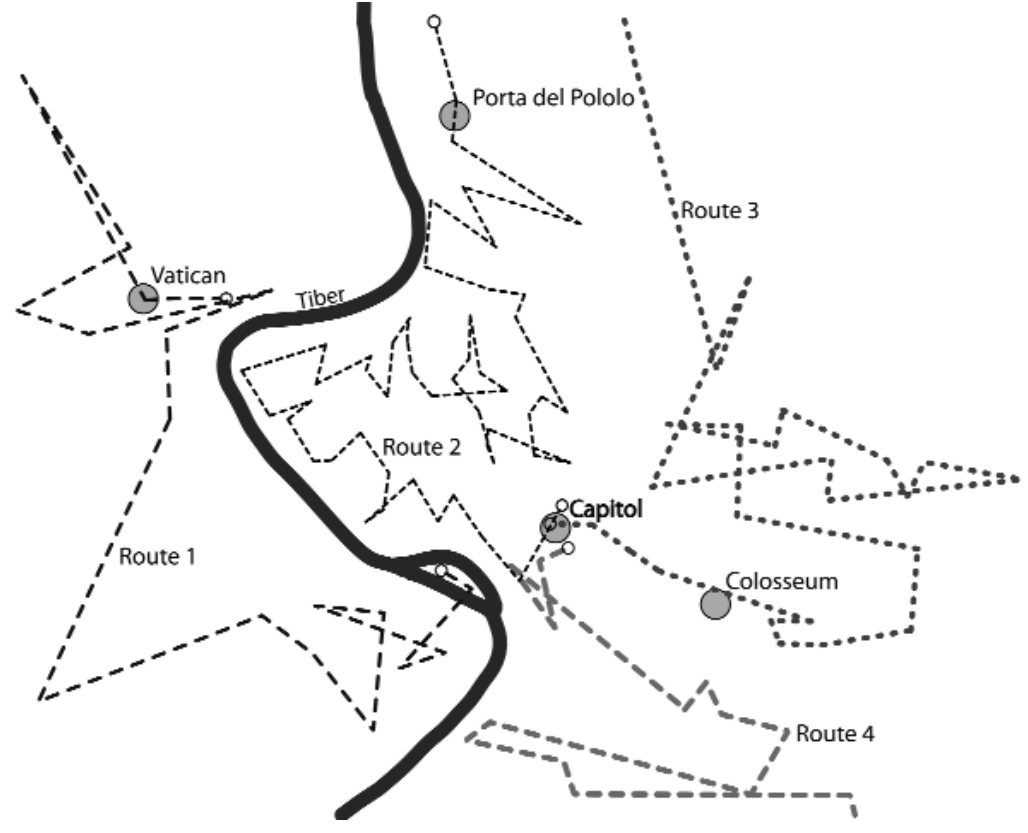

Map of Rome indicating the four routes that link the medieval churches in the second of Palladio's guidebooks, Description of the Churches, 1554

remote one mediated by the 'book', and surely the guidebook's charm lies in the communication by one human being (who knows) to another (who is yet to know) of his or her particular experiences and understanding of a strange town. The crucial thing here is not the sheer availability of information, but that it has already been selected, edited and organised into a coherent narrative or theme by an authoritative person the visitor is willing to trust. The guidebook is as much about the guide as it is about the places and things in the city it describes, whether these are monuments, food, nightlife, where to stay, shopping etc. We, the visitors, want it to be specific not general. The vast majority of the city is necessarily left out, not because it is to be ignored or forgotten, but because the simple act of selection acknowledges that without it being there, nothing of what has been selected would be there either.

Importantly too, the artefact (the city) presented whether by spiels in situ or in the form of a guidebook does not remain in the possession of the guide but is as it were given to the visitor to do with as s/he will and make his/her own mind up about. The guide does not lay claim to the artefact in the way its creator/an artist would.

As Vesely says,

'[...] Consider the experience of reading a plan or map of a particular place. To understand the spatial configuration of a town we have not seen before requires a particular effort. Without outside help [i.e. a guide], only our imagination can guide us through the unknown toward a clearer understanding of the town $[. .$.$] The prominence of certain$ buildings or spaces helps us to move from a random sequence of experiences to a more structured vision of a situational pattern.' A visitor who has in isolation to assemble all the facts and figures, anecdotes, for themselves may be self-taught, self-made even, but not guided. In Huysmans' Against Nature, his hero aesthete Des Esseintes manages to undertake an entire journey to England in his intoxicated imagination without leaving his port of embarkation.

And this brings me back to where I started.

The possibilities of the new digital era for architectural guidebooks exemplify the virtues and vices of the modern outlook: our obsession with history, our desire for autonomy, and our enthusiasm for technology.

\section{History}

Our treatment of the past as a precious object rather than as the source of our traditions has tended to detach us from our own history and its artefacts. As a result museums and 'heritage' have thrived and so latterly have museological attitudes to our cities, especially their historical centres.

It is in the nature of buildings and architecture that they often survive long after the circumstances that brought them into being, or the situation that gave them their meaning and significance. Nevertheless there are many 


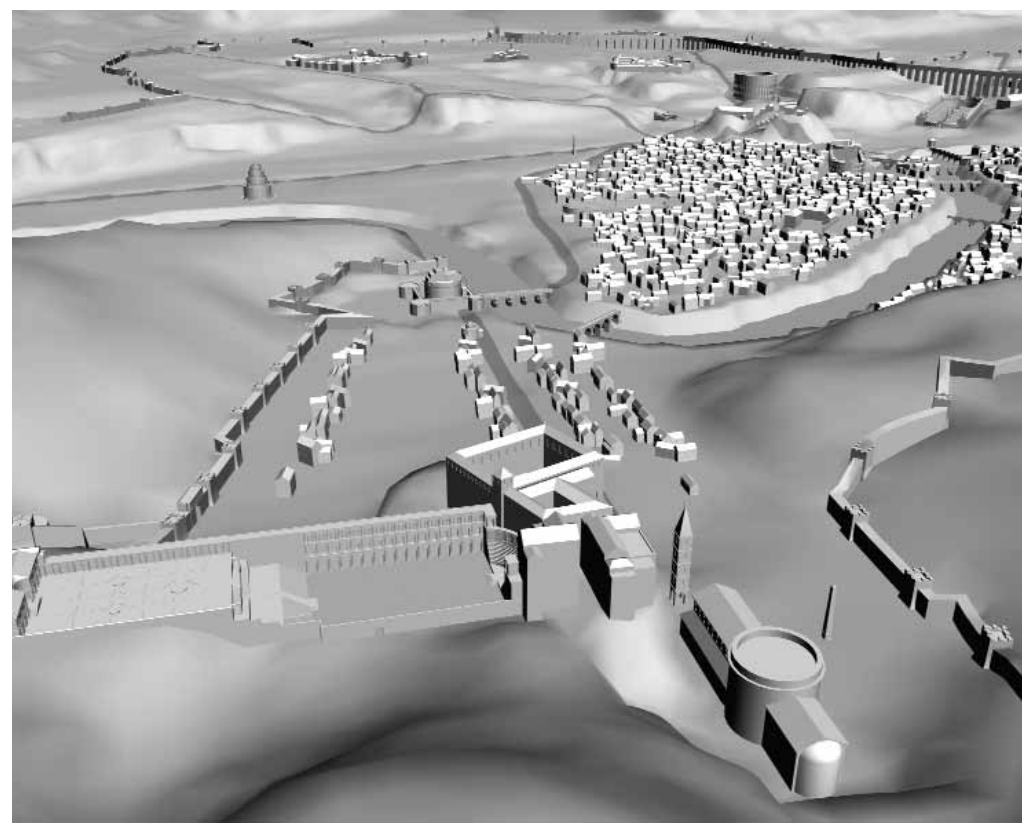

Three-dimensional reconstruction of Rome at the time of Palladio's guidebooks, based on Pirro Ligorio's 'map' of 1552: detail showing the Vatican and the Belvedere

buildings too, maybe hundreds of years old, that are yet to have their true moment of history.

We want the history of our cities to be objective and transparent, not content with plausible myths or anecdotes, we want the truth: but is it fair to expect this of the fabric of our cities, to isolate what we think historically significant and preserve it from the intrusion of new buildings in such a way as to postpone any meaningful dialogue between our past and present, in short, to procrastinate?

The present truth of the Ramblas in Barcelona that many of us will have experienced on urban study tours in recent years as a vibrant cosmopolitan thoroughfare is very different from the truth as George Orwell experienced it in May 1937:

'I could grasp that the Ramblas, which is one of the principal streets of the town, formed a dividing line. To the right of the Ramblas the working-class quarters were solidly Anarchist; to the left a confused fight was going on among the tortuous by-streets, but on that side the PSUC and the Assault Guards were more or less in control. Up at our end of the Ramblas, round the Plaza de Catalunya, the position was so complicated that it would have been quite unintelligible if every building had not flown a party flag. The principal landmark here was the Hotel Colon, the headquarters of the PSUC, dominating the Plaza de Catalunya. In a window near the last O but one in the huge "Hotel Colon" that sprawled across the face they had a machine-gun that could sweep the square with deadly effect.'2

A second historical reading, like
Orwell's double-take, deepens our understanding of our situation.

The freedom of movement we now enjoy in this public space can only be the richer and more poignant for the fact of this episode in its history when that freedom was paralysed.

Certainly I welcome the possibility that digital technology can offer the immediate availability of Orwell's account to the contemporary Ramblas rambler - a veritable 'mobile library'. Invisible realities can in this way be superimposed on perceptible, physical ones.

The association of Orwell and technology, however, summons up another, altogether more sinister spectre, that of surveillance.

'It is possible for the visitor to be located geographically using a global positioning system and to receive information via wireless communications.'

If it is a matter of being lost, any self-respecting architectural sightseer would rather re-locate themselves in the centre of a city by recognisable buildings and street names than by remote satellite grid-reference and disembodied fragments of information.

\section{Autonomy}

This brings me to the second sacred cow of modernity: autonomy, which in many ways is a corollary of individual freedom.

'New kinds of city guides can be invented based on the visitor's

freedom of choice and desire to roam.' Who is a tourist or flâneur but the exemplar of the detached autonomous individual who enjoys his/her immediate surroundings without having particular commitment or obligation towards them or anything very much at stake in them.

The camera obscura (which the authors refer to as the precedent for the display of their model) in order to work needs the observer to be isolated from the thing observed - it at once renders the viewer omniscient and impotent, a nonparticipant in present (or in this case past) reality; just as H. G. Wells' time-traveller is unable to interfere with past events for fear of threatening his own existence, so it seems the urban flâneur must not compromise his/her own autonomy and freedom by getting involved. As we know, this attitude persists once we are outside the exhibition room in the real town, to the extent even that the tiresome local who genuinely wants to 'show you round' must be brushed off for daring to question your selfsufficiency.

And this self-centred attitude is embodied in and encouraged by many of the personal technological devices we carry around with us in the city, their calls on us taking priority over any conversations or interchanges we may be having with our companions. Our behaviour towards others is affected, which isn't to say that etiquette shouldn't evolve too.

The use of personal technology in the name of individual freedom does seem, I'm afraid, to encourage autonomy at the expense of here and now sociability, and this seems anathema in the city. With technology held in such awe we are continuously in danger of it becoming a fetish where it no longer serves real human needs or ethics.

'Lacking access to anything very like the human situation, it is not surprising that digital computers also lack access to anything like human understanding.' ${ }^{3}$

\section{Technology}

But digital technology is only an amoral tool; it can be used for good or ill. The authors see the new technology as encouraging an 'alternative, more flexible approach' to the fixed itineraries of the traditional Palladian guidebook, suggesting that there may be more than one interpretation of a city's phenomena. I welcome this even if some of these 'myths and legends' are erroneous for this seems to me to provide a more fertile ground for debate, collaboration and 
creativity. This after all is what cities are good at.

Guidebooks are apt to turn cities into narratives rather than present them as simultaneities in the way that maps or viewpoints do. What may be possible and interesting for modern technology is to present the city as a series of parallel narratives which cross paths in the manner of certain films like Altman's Short Cuts.

The internet provides a wide range of information types from the

authoritative academic article to the highly personal blog, all of which are equally accessible.'

What is missing from

contemporary guidebooks perhaps is the sense of the city as a palimpsest: what was once here and has now been erased nevertheless still informs what is here now - for example the persistence of the mediaeval street pattern and names in the modern City of London, despite its almost total eradication by the Fire of 1666 ; why this should be is something that the visitor might like to know something more about and the immediate answer may lead to a detour or change of direction or focus.

What digital technology can provide in situ very usefully therefore would be all kinds of library information: e.g. demographics, property ownership for a particular neighbourhood, constructional sections revealing vertical relationships; readings that cannot be discerned from surface appearances, even by the most subtle detective.

Can we access this sort of information on the hoof as well as in a museum? - yes, we can and should be able to, but this sort of comprehensive knowledge is probably of more interest to a professional than a tourist, who I suspect would rather sustain some mystery, some sense of 'cat-andmouse', some sense of incompleteness. What we are after when we go for a walk in an unknown city is more likely to be a stimulus to and revival of our own imaginative, creative and social lives, rather than the total topographical, historical and sociological transparency of our surroundings.

We mustn't endorse technology for its own sake, nor simply for its economic potential, but ask what its ends are. If its ends are to be the continuing emancipation of the individual from social responsibility and recognition, then we are marginalising our humanity and weakening the reason for cities. This is just as sinister a technological outcome for us as a world dominated by Big Brother.

If we ask of Technology,

'Would you tell me please, which way I ought to go from here?'

We will simply receive the reply, That depends a good deal on where you want to get to.'

MARK POWER London

Mark Power is an architect with his own practice in London. In recent years he has been a studio tutor and lecturer at Cambridge and at the Welsh School of Architecture, and published articles in arq, Archis, Scroope and Made. He guides architects and architectural students in Rome and Barcelona.

\section{Notes}

1. Dalibor Vesely, Architecture in the Age of Divided Representation: the question of creativity in the shadow of production (Cambridge, MA; London: MIT, 2004), ch. 2 , pp. $45^{-6}$.

2. George Orwell, Homage to Catalonia (London: Penguin, 1989), p. 112.

3. Hubert L. Dreyfus, 'Misrepresenting Human Intelligence', in The Tradition of Philosophy, ed. by Harrison Hall and Norman Bowie (Belmont, CA: Wadsworth, 1986), p. 300.

4. Lewis Carroll, The Annotated Alice: 'Alice's Adventures in Wonderland' and 'Through the Looking Glass', ed. by Martin Gardiner (New York: Norton, 200o), pp. 88-9.

Letters for publication should be sent to:

Richard Weston

arq

The Welsh School of Architecture

Cardiff University

Bute Building

King Edward VII Avenue

CardiffCF10 3 NB, UK

$\mathrm{T}:+44(29) 20874431$

F: $+44(29) 20874926$

E:WestonR1@cardiff.ac.uk

The Editor reserves the right to shorten letters 